Embedding research in a field-based module through peer review and assessment for learning

Dawn T. Nicholson

Manchester Metropolitan University, UK

School of Science and the Environment, Chester Street, Manchester M1 5GD

Tel: 01612476232

E-mail: d.nicholson@mmu.ac.uk 


\title{
Embedding research in a field-based module through peer review and assessment for learning
}

\begin{abstract}
A case study is presented of embedding research in a final year undergraduate, field-based, physical geography module. The approach is holistic, whereby research-based learning activities simulate the full lifecycle of research from inception through to peer review and publication. The learning, teaching and assessment strategy emphasises the progressive nature of knowledge and skills acquisition, facilitated through multiple opportunities for progressive, formative feedback. Students value the challenging yet rewarding nature of the module and engage with formative activities and peer review. The model demonstrates the value of peer review, fieldwork and research-based learning to facilitate progressive skills development and learner autonomy.
\end{abstract}

\section{Keywords}

Embedding research in the curriculum, peer review, enquiry-based learning, fieldwork, assessment for learning 


\section{Introduction}

Students place great value on learning that is achieved in a research-based environment. This is one of the key conclusions of a wide-ranging review into the research-teaching nexus conducted by Jenkins (2004) and updated by Jenkins et al. (2007). So why do students place such a high value on research-based learning? In part, because there are tangible benefits such as enhanced knowledge and the development of transferable skills, particularly where students are actively involved in enquiry-based research (Healey, 2005a; Spronken-Smith et al., 2008):

"undergraduate students are likely to gain most benefit from research in terms of depth of learning and understanding when they are involved actively, particularly through various forms of inquiry-based learning."

(Healey, 2005a, p183)

Furthermore, Gibbs (1988) points out the compatibility between learning through active engagement with research and Kolb's experiential learning theory (Kolb, 1984, explained by Scheyvens et al., 2008). However, evidence is presented here that students also appreciate the intangible benefits of research-based learning. These include exposure to academia and obtaining answers to curiosity-driven questions about what we do and why we do it (Neumann, 1994).

Mechanisms for embedding research in curricula have been reviewed by Jenkins (2004) and Jenkins et al. (2007) and are the focus of Special Edition 5 of Planet (LTSN, 2003). Examples include the generation of a research proposal (Hill et al., 2004), team-based field research culminating in a research report (Plater et al., 2003), and a student research conference (McGuinness and Simm (2003). There is growing use of online student journals for 
publication of undergraduate research (Walkington, 2008), and Walkington and Jenkins (2008) offer ten strategies for using publication to embed undergraduate research in the learning experience. Being one of the primary contexts in which geography research is conducted, fieldwork itself presents an important mechanism through which to promote enquiry-based research (Scott et al., 2006). Fieldwork can facilitate the development of a range of intellectual, technical and personal skills (Hovorka and Wolf, 2009). Furthermore, field-based learning also provides opportunities for students to engage both in applied research and in the process of research (Fuller et al., 1996; Fuller et al., 2000).

Zetter (2002) suggests proactive strategies for embedding teaching - research links across an entire curriculum and some Geography departments have implemented such strategies (e.g. Hill et al., 2004; Huggins et al., 2007). When research is embedded at a strategic level across departmental curricula, there is increased capacity to pitch teaching and research links at the right level, to facilitate progressive development of skills, and to make use of a multitude of different mechanisms for embedding research. That said, research can be very effectively embedded within a single module and may offer a more focussed, integrated and coherent opportunity to expose students to the complete life-cycle of a research project. There are few published cases where the whole research life cycle is embedded within a module from inception through to publication. Several, such as the StuP project (McKendrick et al., 2003), take students on a journey through the design and implementation of field-based research through to some form of peer-reviewed write-up or publication in an online journal. However, students are not normally involved as reviewers in these peer review processes.

This paper presents a case study of a final year undergraduate field-based physical geography module in which research is embedded throughout. A lifecycle approach to research is adopted that includes the provision of theoretical underpinning, preparatory field training, research design, implementation in collaborative teams, preparation of a journal 
article, and engagement in the peer review process. The aim is to provide an authentic learning experience that mirrors professional environments, processes and relationships. This case study has two attributes of particular note: (a) the progressive and developmental nature of the field-based research, with multiple opportunities built-in for formative assessment and feedback to facilitate experiential learning and development of metacognition in a nonthreatening environment; and (b) the involvement of students in the peer review process, acting both as reviewer and reviewee.

The module approach incorporates active, enquiry-based learning in a field setting and is both research-based and research-tutored following Healey's conceptual representation of the links between research and curriculum design (Figure 1). In this representation (Griffiths, 2004; Healey, 2005b), the relationship between teaching and research is expressed via two axes, one depicting the nature of student participation and the other depicting the research emphasis. Thus the research-tutored approach sees students learning about research matter, or content, as engaged participants in small group tutorials. In the research-based approach, staff and students learn together through enquiry in the field and through the peer review process.

\section{Background to the Field Research and Analysis module}

A week-long summer field course to the Jostedals region of Norway is a central component of the module Field Research and Analysis. Prior to the field course, two half-day workshops introduce the module, the field area and planned activities. This preparatory work helps make the best use of the limited time in the field as recommended by Bradbeer (1996). Logistical arrangements are dealt with, students are guided in the preparation of proposals for field project work, and the two module assignments are set. The field course includes four days of field research training and development primarily in support of assignment one, and three 
days of small group project work primarily in support of assignment two. Post-fieldwork seminars occur throughout term one of the final year and focus on supporting students through completion of the two assignments. The module is worth 20 credits, equivalent to 200 hours of student effort. Typically, student numbers on the module range from 8-12. There has been much discussion in the literature about the implications of increasing resource constraints on fieldwork provision in geography (e.g. Haigh and Gold, 1993; Higgitt, 1996; McEwen, 1996; and more recently, Hovorka and Wolf, 2009) and such constraints make small fieldwork groups somewhat atypical. In this module, final year residential fieldwork opportunities are optional and costs are met entirely by the student participants. Group size is therefore limited at the lower end by cost and staff workload considerations, and at the upper end by logistical constraints.

On successful completion of the module students are expected to be able to:

a) Demonstrate evidence of

- field observation and recording,

- field data presentation and analysis, and

- integration of field observations and data with theoretical concepts for a variety of mountain geomorphology landforms, processes and materials.

b) Design and implement a detailed geomorphic investigation in a field situation.

c) Analyse and interpret data from the field investigation and synthesise and integrate the findings into a journal article.

\subsection{Module assessment}

The assessment strategy for the module demonstrates constructive alignment and is designed to enhance learning opportunities for students as well as provide a mechanism for grading (Biggs, 1996). Feedback through formative assessment is intrinsic throughout, and 
further reflects the desire to support progressive student learning through assessment (Gibbs and Simpson, 2004).

Assignment one (50\%) requires students to construct a three-part, evidence-based portfolio demonstrating their achievement of the three components of learning outcome (a). In each, students provide evidence to support their claim for that learning outcome and provide a 500word explanatory commentary. Students are provided with examples of evidence claims (Table 1) but the open-ended nature of the assignment is designed to encourage student autonomy and innovation.

Table 1 here.

Assignment two (50\%) requires students to design and implement a detailed geomorphic investigation in a field situation, to analyse and interpret the data collected and synthesise and integrate the findings into an objective, 3000-word scientific report in the form of a journal article. These field investigations take place in Fabergstølsdal, an outlet valley to the north east of the Jostedals ice cap, and have included lichen-dating of moraine sequences, verification of paraglacial slope development models, mapping of small-scale glacial erosional forms, and studies of meltwater hydrology and water quality. A major part of this assignment is student participation in an anonymised peer review process simulating that for the publication of professional academic research.

\subsection{Simulating an authentic research lifecycle}

A number of linked learning activities simulate the full lifecycle of professional research processes: 
a) An opportunity to publish a chapter in the module Field Guide (see section 3.1).

b) Research design for a field investigation, including formulation of hypotheses, development of a sampling strategy and identification of appropriate data collection methods.

c) Application and testing of field research techniques and sampling strategies in a collaborative setting.

d) Implementation of collaborative field investigations.

e) Analysis and presentation of field data.

f) Preparation of individual journal articles.

g) Participation in a peer review process leading to final decisions on 'publication'.

\section{Pre-fieldwork activities}

\subsection{Field Guide}

During the pre-field course workshops, students select a topic from a list provided to write a two-page contribution to the module Field Guide; Introduction to the Geomorphology of Norway. Example topics include small scale glacial abrasion forms, periglacial landscapes and processes, mass movement in de-glaciated terrain, hydro-electric power in a mountainous environment, human impacts and resources, and geomorphic applications of lichenometry. This activity familiarises students with relevant literature and encourages them to begin formulating research questions pertinent to the geomorphology of the field area. Students submit their work prior to the field course and the best quality submissions are included in the final Field Guide distributed to the cohort before departure. This element of informal peer review encourages students to take this formative assessment task seriously. A set of rules for authorship and publication of the Field Guide has been established (Table 2). Thus far, no students taking the module have had their work completely rejected, although 
substantial editing has been necessary for some contributions. The Field Guide has expanded each year that the module has run and now includes a number of appendices focussing on specialist field techniques.

Table 2 here.

To emphasise links between field observations and underpinning theory, students are asked during the field course to explain their Field Guide topic to the cohort at an appropriate opportunity (Figure 2). The list of topics is devised such that every student encounters at least one opportunity to deliver this informal 'presentation'. Thus, a student who has written a contribution on the use of lichenometry as a dating tool in glacial environments, for instance, will be asked to give an informal explanation when this technique is first practised in the foreland of Nigardsbreen glacier (Figure 3).

\subsection{Research proposal}

Between the two pre-field course workshops students work in pairs and threesomes to prepare and submit a collaborative proposal for their field research. Proposals must review relevant literature, identify a number of research questions, present aims, objectives, and one or more testable hypotheses, and design the complete programme of research. Small group tutorials are held to discuss and refine proposals as appropriate and address any ethical or logistical issues.

\section{Field research training}

The field course lasts for seven days and takes place in late summer (between students' second and third years) to take advantage of optimal weather conditions. The field course has 
two distinct parts: The first four days provide opportunities for students to practice advanced field techniques at a variety of locations. Students work either as a whole cohort or in subgroups and this work forms the basis for the assignment one portfolio. The final three days are based at Fabergstølsdal for the research projects.

During the first part of the field course, a variety of contrasting (e.g. tundra plateaus, glacier forelands, and rugged, mountainous terrain) and often spectacular environments are visited (Figure 4). At each location, students are introduced to advanced field techniques and work in small groups to design sampling strategies, record observations and collect data that can be used to conduct enquiry-based geomorphic research. The features observed and the data collected are closely allied to the author's own research interests and her colleagues. Field and follow-up discussions centre around identifying contemporary research issues and gaps in understanding.

One example of a field activity takes place in the foreland of Nigardsbreen glacier (Figure 3) where exposed bedrock bears evidence of ice erosion. Spatial and temporal patterns of lichen growth and rock weathering are used as proxies for glacier advance and retreat throughout the twentieth century. Students are encouraged to practise both techniques and to engage in ancillary duties (e.g. note-taking and recording location details). Other activities taking place during the first part of the field course include a visit to a dam and hydro-electric power station, fabric analysis of blockstreams, morphometry of ploughing boulders and patterned ground, sediment logging in exposed sandur gravels, and a glacier tour to observe and record supraglacial and meltwater forms. In the evenings, students collaborate to compile and analyse data using laptops. Back in the UK, all data are uploaded onto the intranet and made available to the whole cohort. 
During the final part of the field course, students conduct their research projects in collaborative groups of two or three, simulating common practice in professional academic research teams (Figure 5). While the tutor makes occasional supervisory visits, students largely work independently, guided by the plans set out in the agreed research proposals. These projects parallel the academic and logistical processes necessary for final year dissertation work and informal feedback from students indicates they hugely value the opportunity to have a dry run before the real thing.

\section{Post fieldwork}

\subsection{Weekly seminars}

During term one of their final year students attend weekly module seminars. These are entirely student-centred, aimed at maximising potential learning and achievement through preparation of the assignments. Initially, seminars focus on active learning in the context of data analysis and presentation. Active learning can be considered as learning that takes place through doing and thinking, but specifically, linking the doing and the thinking (Gibbs, 1988). Active learning methods used here include small group work and problem solving (Scheyvens et al., 2008) - students examine the data, develop and share ideas about effective presentation and analysis, and enter into discussions about the relationships between findings and accepted theory.

\subsection{The peer review process}

In the final few weeks of the module, weekly seminars focus on developing skills in the interpretation of research findings, scientific writing and peer review. The product required for assignment two must be written in the style of a paper published in an appropriate scientific 
journal. The process of submitting the assignment is designed to simulate the anonymised peer-review process undertaken by professional academics seeking publication of their research. Elsewhere in the literature, peer review processes are sometimes regarded as a mechanism for addressing resource issues such as the burden of marking in large classes (Higgitt, 1996; Kent et al., 1997; Hughes, 2001; Langan and Wheater, 2003) and also an opportunity for enhanced, co-operative learning (e.g. Langan and Wheater, 2003; Le Heron et al., 2006; Scheyvens et al., 2008). In this case, the main aim was to dissociate students from the context of a University assignment, and to engender a professional, authentic, context. The four stages in the peer review process are outlined in Table 3.

Table 3 here

There is plenty of evidence to suggest that given appropriate criteria, students are capable of quality, accurate peer assessment (e.g. Hughes, 2001; Langan and Wheater, 2003). That said, careful management of the process is required if it is to be successful for both students and staff (Pharo and de Salas, 2009). Issues around accuracy of marking were avoided in this module since the peer review process was designed only to provide formative feedback at the draft stage (Pain and Mowl, 1996). The peer review process is facilitated with a modified version of the anonymised reviewer comment form used by the journal Earth Surface Processes and Landforms. A space is provided for students to enter an indicative grade to encourage close student engagement with the assessment criteria and grade descriptors provided along with the assignment briefing. The reviewer is asked to indicate if the paper should be published and is any modifications are required. This maintains the reality of the peer review process and encourages students to be bold in their judgements. Students are asked to preserve the realism of the professional process by not communicating with peers each other about the assignment during the review phase. It is not possible to police this - any 
more than it is in professional peer review. However, anecdotal evidence suggests students are keen to preserve their anonymity to avoid open criticism from, or conflict with, peers.

\subsection{Examination of reviewer feedback on a submitted paper}

To fully prepare students for peer review, one seminar is given over to a detailed examination of the process. This begins with a mechanistic overview of the process using a flow diagram framework. A set of actual review documents generated by submission of a research paper by the author is then considered. To set that research paper in context, students consider the background to the research topic, the research development process, research design and implementation, data analysis and the writing up process undertaken by the author. This outline parallels the activities being undertaken by students at that time and underlines the authentic nature of the assignment.

In the next part of the seminar, editor and reviewer comments on the submitted paper are displayed on screen and explored in detail with the students. Some of the subtleties of the review process are discussed, including disagreements, reviewer idiosyncrasies, contradictions between reviewers, editors mark-up and house styles, and problems arising from fundamental factual or numerical errors. The importance of consistency and accuracy are discussed. The seminar provides students with an invaluable and personal insight into the publication process.

\section{Evaluation of the peer review process}

An anonymous end-of-module evaluation is conducted each year. Students are asked thirtyfive open and closed questions on issues including organisation (e.g. documentation, learning outcomes, and class contact), content (e.g. relevance and scope), field activities (e.g. 
arrangements and academic content), assessment (e.g. workload, criteria, and methods), feedback (e.g. nature and promptness), and learning resources (e.g. online support and tutor communication). Students are also asked to what extent they found the module rewarding, stimulating, or difficult, and are given the opportunity to add free text comments on the best and worst aspects of the module, and areas for improvement. Some outcomes from these evaluations are now considered.

\subsection{Student views on the process}

Because a standard Departmental module evaluation proforma was used, students were not specifically asked about the peer review process. Nevertheless, it is clear from responses that they find this one of the more challenging, yet rewarding elements of the module. They commented on three aspects in particular; reviewing other's work, receiving interim feedback on a draft assignment submission, and the opportunity to engage in an authentic process.

Students rarely have the opportunity to read other students' work. They found the process helpful and informative and valuable for reflecting on their own work:

"I found it useful reviewing another student's paper as this focussed my attention on some parts of my own work".

This verifies the contention by Pharo and de Salas (2009) that peer assessment can enhance self awareness and self evaluation as well as enabling critical judgement of others' work.

Students highly valued the opportunity to receive feedback on a draft piece of work prior to the final submission - a practice that is relatively uncommon in Higher Education except for final year dissertations / independent projects: 
"Very valuable experience - very rarely do you get feedback on work before it's marked."

and

"I really like the fact that we had a chance to do a draft version of our work and peer review someone else's!"

In addition to feedback from the tutor (acting as editor) each student received feedback from their anonymous reviewer. Some students found the quality of feedback from peers unhelpful:

"I found some points raised by the reviewer of my own paper confusing and very unconstructive."

This is not unusual (e.g. Pharo and de Salas, 2009) and may reflect a lack of experience of exposure to other's work. From the tutor's perspective, peer feedback comments on student work were quite variable in content and quality. In some cases, students highlighted mainly functional weaknesses such as the number of references cited, overall organisation and structure, typographical and grammatical errors, omissions (e.g. aims and objectives, figure captions, photograph annotations), poor presentation and writing style.

Students were positively influenced by work that was well written and presented, a tendency that has been noted elsewhere (Gibbs and Simpson, 2004). Despite presentation being just one of a number of assessment criteria, most students emphasised the quality of presentation in their feedback comments. In some cases, student expectations of their peers were somewhat ambitious for an undergraduate assignment. Their paraphrased feedback on student work includes: 
- the work is unoriginal (lots of other papers have been written on the same topic)

- you should have created your own lichen curve [a dating reference curve]

- the work could advance current theory.....

In most cases, however, student comments adhered closely to the assessment criteria, were perceptive and indicated high level, deep learning processes at work. Criticisms included the lack of justification for the research, lack of a conclusion (was the hypothesis proved or disproved?), insufficient reference to peer-reviewed publications, irrelevant or unsupported arguments, lacking comment on the significance or implications of findings, unnecessary over-complication.

In addition, some students identified important factual errors and omissions in data analysis and interpretation and suggested alternative, preferable statistical or analytical methods. Some also highlighted fundamental errors in research design, particularly sampling strategies. Most students behaved very professionally, offering both positive and encouraging comments alongside constructive criticism and feedback.

Students valued the authenticity of a real-world process and especially exposure to actual reviewer and editor comments:

"Peer review is a good idea and I suggest that it continues - the fact that it parallels the real process made it fun."

This supports Rust's (2002) contention that assessment activities imitating real-world processes can have a beneficial impact on student learning: 
“Assessment tasks are far more likely to appear relevant if they are 'real-world' tasks, i.e. the student can see why in the real-world someone might undertake such a task, and if there is the notion of a 'real' audience who might want to receive the resulting product."

Rust (2002, p150)

\subsection{Effect on marks}

The module has so far run on two occasions. For the first year only, a record was kept of the indicative mark awarded by the tutor for the draft paper (i.e. pre-peer review). For a cohort of twelve students, the average improvement in mark from draft to final submission was $10 \%$, ranging from 3 to $31 \%$. This includes an exceptional case where a student improved their mark from $37 \%$ to $68 \%$ - a reflection of an ill-prepared draft. For other students, the maximum increase in mark was $15 \%$. Typically, the average module mark is $58-60 \%$, and $58 \%$ of students achieve either an upper second or first class module mark. These values are a little higher than for most other final year modules. It is unclear if this reflects successful learning and assessment methods or if it is simply that more motivated students opt for field-based study.

\subsection{The tutor's experience}

Informal queries from colleagues about the peer review process suggest concerns around two aspects:

The first is an apparent doubling of marking load for the tutor, A considerable, but commensurate effort is given to assessing and providing feedback on draft papers. Copies of drafts, together with manuscript comments and completed feedback proformas, are retained 
for future reference. However, marking of the final papers requires much less effort because (i) the process is treated as entirely summative and no feedback is provided, and (ii) assessing and grading is a relatively simple matter of confirming that feedback on draft papers has been addressed. The use of a grade descriptors and standards grid (Table 4) also facilitates the grading process.

The second concern is around the opportunity for students to submit draft work for feedback. Student work is assessed for many reasons. Undue emphasis is often placed on assessment for the purpose of grading, but arguably of greater importance for cultivating student ability, is assessment designed to "promot[e] student learning by providing the student with feedback" (QAA, 2006, p4). The role of formative feedback in assessment is also highlighted in University assessment policy (MMU University Assessment Framework, 2008, p1):

"The University recognises the importance of both formative and summative assessment in the student experience and expects it to be integrated into all curriculum planning......"

For this assignment, the evidence suggests that learning clearly does take place during the review process (i.e. between the submission of draft and final papers) - partly through acting upon the feedback provided but also through reviewing the work of others. Another benefit of embedding feedback prior to final submission is that it mirrors professional practice in academia, as well as in other public and private sectors. Rehearsing real-world practices in this way is fully compatible with our desire to develop employable graduates and does not have any adverse implications for maintaining standards in summative assessment. It is also fully compatible with a desire to use assessment for learning and engagement.

\subsection{General remarks}


The marks data presented above are not sufficiently robust to claim that this model of curriculum delivery is certain to result in a significant performance improvement among students. However, together with student evaluation comments, personal reflections on the peer review activity, and support from published literature, evidence suggests this approach to peer review has considerable potential to effectively embed research, engage students, provide an authentic learning and metacognitive experience.

\section{Student feedback on the module}

The peer review process is but one element of a module containing a number of interconnected structural and academic components. Links between teaching and research are developed throughout and this, together with the overseas fieldwork experience, has a very positive influence on overall student evaluation of the module (Table 5). Although there were some negative feedback comments and criticisms, these mostly centred around practical issues and preferences relating to meals, travel arrangements and accommodation. Students particularly valued opportunities for active participation, informal networking (Figure 6) and autonomy. Feedback also suggests that students were intellectually challenged, and were able to rise to that challenge. The rewards arising from being challenged have been noted by others in the context of enquiry-based learning and fieldwork (Livingstone and Lynch, 2000; Panelli and Welch, 2005). Students enjoyed flexibility in the assessment activities and informality in teaching delivery. Unusually, some students cited assessment, and the peer assessment process in particular, as one of the best features of the module. While some students highlighted their acquisition of new knowledge, others recognised that they had acquired important new skills.

\section{Discussion}


Self and student evaluation of the module raises a number of generic issues around effective learning in a research-based environment.

\subsection{Assessment for learning}

Learning may be enhanced when assessment is treated as part of the learning process rather than merely as a means to grade achievement (Bostock, 2001). This 'assessment for learning' approach provides a 'glass half full' environment in which mistakes can be regarded as opportunities to improve rather than as failures. Formative feedback on draft materials also provides an opportunity to ensure that assessment criteria are fully understood (Blackman, 2003). Assessment tasks ideally placed to promote advanced learning, skills acquisition and metacognition (Harvey and Burrows, 1992) include peer review and field-based enquiry activities. Indeed, as Healey says (2005a, p197):

"If there is to be a closer alignment between the needs of staff and the benefits for students, a new pedagogy for the twenty-first century may be required. The rediscovery of a curriculum devised around inquiry-based learning would be a strong contender"

The module design encompasses the recommendations of Rust (2002) pertaining to the impact of assessment on student learning. These include constructive alignment between learning outcomes and assessment tasks (Biggs, 1996), use of assessment tasks that both resemble the real-world and promote active engagement, embedding formative activities, and increasing student preparedness for subsequent research by making use of self and peer assessment (Blackman, 2003). 


\subsection{Progressive learning}

It is widely held that as students advance through their higher education career, there ought to be an increasing emphasis on higher order cognitive skills and deeper learning (James, 1998). In the curriculum model presented here, students first have an opportunity to implement specialist research techniques in the relatively 'safe' environment of whole-cohort activities in the early part of the field course. At this stage, only minor, co-operative, decisions need to be made about sampling strategies and recording methods. Later in the field course, students are challenged to make more significant decisions about research design and hypothesis testing, data analysis and interpretation. A similar progressive approach to skills development is taken with respect to peer review: Initially, the tutor makes decisions about authorship of Field Guide contributions but the process is fully explained to students. Later, students experience informal peer review when presenting their Field Guide contribution in the field. Finally, students participate in a peer review process designed to simulate reality. This in-built progression provides multiple opportunities for students to reflect upon their work and to learn from experience, effectively closing the loop of the Kolb experiential learning cycle (Kolb, 1984). Further progressive learning opportunities are available via progressive development of field and research skills in a concentrated period of time. The short time period of the fieldwork and informal nature of the group enables adjustments to be made at subsequent levels of progression based on performance at earlier levels. This is compatible with the pedagogical strategy of Just in Time Teaching (JiTT) (Novak et al., 1999) that suggests more effective learning is achieved where there is a rapid feedback loop between student activity and subsequent class time. The module itself is also progressive in providing an excellent foundation for students to performance enhancement in the 40 -credit final year dissertation, a conclusion also reached by Tinsley (1996) with respect to second year fieldbased project work. While this unit is completed by the end of the autumn term, dissertations 
are not submitted until after Easter - thus there is ample opportunity for students to reflect upon, and learn from their experience.

\subsection{Student autonomy}

The acquisition of learner autonomy can be regarded as a gradual process by which students increase awareness of their own strategies, needs and goals as a learner. Progression maximises such learning by internal re-structuring and reconsideration of approaches and processes (Thanasoulas, 2000). At the start of this module there was a sense of nervousness among students borne of the open-ended nature of assignment one and the lack of restriction over topic focus for assignment two. However, these qualms were rapidly extinguished as students gained a better understanding of the processes involved, increased confidence in their own ability and discovered the freedom to take ownership of their own learning (Bostock, 2001). Others have argued that peer assessment, for example, can lead to a sense of empowerment among students (Stanier, 1997), and that they value the sense of autonomy that can be gained from field-based learning (Pawson and Teather, 2002). The candour expressed by the author during the peer review seminar (presenting a personal paper with actual reviewer comments) further enhanced the open style of teaching adopted throughout. It is suggested that this created a sense of equality between tutor and students in which all were perceived to be located at different points along a continuum of learning and motivation. Students are treated throughout, in effect, as inexperienced members of Faculty. Thus learner autonomy can be enhanced through curriculum design and delivery. In addition, the field course is designed in such a way that there is a progression from both dependent participant (activities tutor-defined) and independent observer (parameters student-defined), to autonomous participant (parameters and activities student-defined), following the Kent et al. (1997) categorisation of fieldwork. 


\subsection{Transferable skills, employability and professional practice}

It is a commonly held perception that students dislike 'skills' teaching and often fail to appreciate the depth and range of skills they have acquired (Blackman, 2003; Monks et al., 2006). Despite this, students valued the module seminars, doubtless reflecting the immediacy and tangibility of links between the seminars and assignment work. Furthermore, the JiTT approach (Novak et al., 1999) enhanced student ownership of class time in a way that made it more profitable and rewarding. The module facilitates the development of various employability skills (e.g. problem solving, communication and presentation skills, and collaborative enquiry). However, one area for future improvement will be to make explicit links between acquired skills and personal development planning processes. This will encourage better metacognition and improve students' self-evaluation to directly and positively impact on their employability. A less tangible benefit arising from the module is an increased sense of pride derived from engaging in activities that parallel professional practice.

\subsection{The value of field-based learning}

Fieldwork provides an extraordinarily valuable learning experience, providing opportunities for active, enquiry-based learning, engagement with authentic processes, development of transferable skills and enhancement of social networks (Fuller et al., 2000; Pawson and Teather, 2002; Scott et al., 2006; Hope, 2009). While fieldwork is not appropriate for all disciplines, it does offer a superb mechanism for embedding and enhancing links between teaching and research (Edwards, 2003; James et al., 2003). That said, the general pedagogic approach presented herein is transferable across most disciplines, whether or not fieldwork is a component of the curriculum. For example, in most disciplines there is a need to deliver techniques training (e.g. in the laboratory, the arts studio, the workshop, or the computer room). So, in place of a Field Guide as presented here, students could be asked to contribute 
to a Techniques Guide focussing on appropriate instructive elements of the curriculum, and associated informal presentations could form a part of in-class activities. Moreover, other activities discussed here (e.g. peer review, enquiry-based learning and the presentation of advanced investigative work) underpin many final year 'capstone' activities and could be integrated into curricula in the absence of fieldwork.

\section{Conclusions}

This paper sets out a module-based approach to curriculum design in which the teachingresearch nexus is positively and effectively encouraged. The model is of holistic and progressive delivery, embedding a research-based approach, with peer review and assessment for learning at its heart. The approach provides a glimpse into real-world processes and facilitates collaborative learning. From a geographer's perspective, it also celebrates the scientific and pedagogical value of field research. Designing and developing a curriculum in which there are strong links between research and teaching promises considerable benefits for staff (Jenkins et al., 2007). Not least of these are the more tangible benefits of potential time savings in preparing class materials, teaching field or laboratory techniques, identifying field locations and identifying appropriate reading materials. However, the less tangible benefits may actually be more attractive. These include the immense satisfaction gained from educating and motivating young academics in the fascinating world of disciplines that have so engaged us, but in such a way that they are also fully equipped to develop and mature as professional graduates.

\section{Acknowledgements}

The author would like to acknowledge the assistance of undergraduate student participants in providing valuable feedback on the module and for being a pleasure to work alongside. 
Grateful thanks are also due to three anonymous reviewers for insightful feedback on an earlier version of the manuscript.

\section{References}

Biggs, J. (1996) Enhancing teaching through constructive alignment, Higher Education 32(3), pp. 347-364.

Blackman, D. (2003). Can research methods ever be interesting? Active Learning in Higher Education, 4(1), pp. 39-55.

Bostock, S. (2001) Student Peer Assessment (York: Higher Education Academy) Available at: http://www.heacademy.ac.uk/assets/York/documents/resources/resourcedatabase/id422 student peer assessment.pdf (accessed 13 October 2009).

Bradbeer, J. (1996) Problem-based learning and fieldwork: a better method of preparation? Journal of Geography in Higher Education, 20(1), pp. 11-18.

Edwards, S. (2003) Examples of integrating field-based research and teaching in Geography, Earth and Environmental Sciences, Planet, 5, pp. 19-20.

Fuller, I., Edmondson, S., France, D., Higgitt, D. and Ratinen, I. (1996) International perspectives in the effectiveness of geography fieldwork for learning, Journal of Geography in Higher Education, 30(1), pp. 89-101.

Fuller, I., Rawlinson, S. and Bevan, R. (2000) Evaluation of students learning experiences in physical geography fieldwork: paddling or pedagogy? Journal of Geography in Higher Education, 24(2), pp. 199-215.

Gibbs, G. (1988) Learning by Doing: A Guide to Teaching and Learning Methods (London: Further Education Unit) Available at http://www2.glos.ac.uk/gdn/gibbs/index.htm (accessed 7 October 2009).

Gibbs, G. and Simpson, C. (2004) Conditions under which assessment supports students' learning, Learning and Teaching in Higher Education, 1, pp. 3-31. Available at 
http://www2.glos.ac.uk/offload/tli/lets/lathe/issue1/articles/simpson.pdf (accessed 14

October 2009).

Griffiths, R. (2004) Knowledge production and the research-teaching nexus: the case of the built environment disciplines, Studies in Higher Education, 29(6), pp. 709-726.

Haigh, M. and Gold, J. R. (1993) The problems with fieldwork: a group-based approach towards integrating fieldwork into the undergraduate curriculum, Journal of Geography in Higher Education, 17(1), pp. 21-32.

Harvey, L. and Burrows, A. (1992) Empowering students, The New Academic, 1(3), pp. 1-3. Healey, M. (2005a) Linking research and teaching to benefit student learning, Journal of Geography in Higher Education, 29(2), pp. 183-201.

Healey, M. (2005b) Linking research and teaching: exploring disciplinary spaces and the role of inquiry-based learning, in: R. Barnett (Ed.) Reshaping the University: New Relationships Between Research, Scholarship and Teaching, pp. 67-78 (Maidenhead: McGraw-Hill / Open University Press).

Higgitt, M. (1996) Addressing the new agenda for fieldwork in Higher Education Journal of Geography in Higher Education, 20(3), pp. 391-398.

Hill, J., Woodland, W. and Spalding, R. (2004) Linking teaching and research in an undergraduate fieldwork module: a case study, Planet, 13, pp. 4-7.

Hope, M. (2009) The importance of direct experience: A philosophical defence of fieldwork in human geography Journal of Geography in Higher Education, 33(2), pp. 169-182.

Hovorka, A. J. and Wolf, P. A. (2009) Activating the classroom: geographical fieldwork as pedagogical practice, Journal of Geography in Higher Education, 33(1), pp. 89-102. Huggins, R., Jenkins, A. and Scurry, D. (2007) Developing Undergraduate Research at Oxford Brookes University. Recommendations and Models for Future Development. Available at http://www2.warwick.ac.uk/fac/soc/sociology/research/cetl/ugresearch/developing ug res earch at brookes.pdf (accessed 27 November 2010). 
Hughes, I. (2001) But isn't this what you're paid for? The pros and cons of peer and self assessment, Planet, 2, pp. 20-23.

James, P. (1998) Progressive development of deep learning skills through undergraduate and postgraduate dissertations Educational Studies, 24(1), pp. 95-105.

James, P., Heinson, G. and Schmidt, A. (2003) Linking teaching and research in the undergraduate fieldwork training programme at the University of Adelaide, Planet 5, pp. 16-18.

Jenkins, A. (2004) A Guide to the Evidence on Teaching-Research Relations (York: Higher Education Academy).

Jenkins, A., Healey, M. and Zetter, R. (2007) Linking Teaching and Research in Disciplines and Departments (York: Higher Education Academy)

Kent, M., Gilbertson, D. and Hunt, C. (1997) Fieldwork in geography teaching: a critical review of the literature and approaches, Journal of Geography in Higher Education, 21, pp. 313331.

Kolb, D. A. (1984) Experiential Learning: Experience as the Source of Learning and Development (Englewood Cliffs, NJ: Prentice-Hall).

Langan, A. M. and Wheater, C. P. (2003) Can students assess students effectively? Some insights into peer-assessment, Learning and Teaching in Action, 2(1), pp. 1-7.

Le Heron, R., Baker, R. and McEwen, L. (2006) Co-learning: re-linking research and teaching in geography, Journal of Geography in Higher Education, 30(1), pp. 77-87.

LTSN (Learning and Teaching Support Network) (2003) Linking Teaching and research and Undertaking Pedagogic Research in Geography, earth and Environmental Sciences. Planet Special Edition 5. Available at http://www.gees.ac.uk/planet/index.htm (accessed 13 October 2009).

Livingstone, D. and Lynch, K. (2000) Group project work and student-centred active learning: two different experiences, Studies in Higher Education, 25(3), pp. 325-345. 
McEwen, L. (1996), Fieldwork in the undergraduate geography programme: challenges and changes, Journal of Geography in Higher Education, 20(3), pp. 379-384.

McGuinness, M. and Simm, D. (2003) Linking teaching and research through Departmental research conferences for student project work, Planet Special Edition 5, pp.21-24.

McKendrick, J., Mooney, E. and McWilliams, C. (2003) Writing for research users: briefing papers as coursework. Available at http://www.gees.ac.uk/linktr/McKendrick1.htm (accessed 27 November 2010).

MMU (2008) University Assessment Framework. Available at http://www.celt.mmu.ac.uk/assessment/framework/MMU Assessment Framework.pdf (accessed 8 October 2009).

Monks, K., Conway, E. and Ni Dhuigneain, M. (2006) Integrating personal development and career planning: the outcomes for first year undergraduate learning, Active Learning in Higher Education, 7(1), pp. 73-86.

Neumann, R. (1994) The teaching-research nexus: applying a framework to university students' learning experiences, European Journal of Education, 29(3), pp. 323-339.

Novak, G. M., Patterson, E. T., Gavrin, A. D. and Wolfgang, C. (1999) Just in time teaching, American Journal of Physics, 67(10), pp. 937-938.

Pain, R. and Mowl, G. (1996) Improving geography essay writing using innovative assessment, Journal of Geography in Higher Education, 20(1), pp. 19-31.

Panelli, R. and Welch, R. V. (2005) Teaching research through field studies: a cumulative opportunity for teaching methodology to human geography undergraduates, Journal of Geography in Higher Education, 29(2), pp. 255-277.

Pawson, E. and Teather, E. K. (2002) 'Geographical Expeditions': assessing the benefits of a student-driven fieldwork method, Journal of Geography in Higher Education, 26(3), pp. 275-289.

Pharo, E. and de Salas, K. (2009) Implementing student peer review: opportunity versus change management, Journal of Geography in Higher Education, 33(2), pp. 199-207. 
Plater, A., Boyle, J. Willis, K. and Morse, A. (2003) Santa Cruz field course: developing team research expertise, Planet Special Edition 5, pp. 24-26.

QAA (2006) Code of Practice for the Assurance of Academic Quality and Standards in Higher Education. Section 6: Assessment of Students (Mansfield: Quality Assurance Agency). Available at http://www.qaa.ac.uk/academicinfrastructure/codeOfPractice/section6/COP AOS.pdf (accessed 14 October 2009).

Rust, C. (2002) The impact of assessment on student learning, Active Learning in Higher Education, 3(2), pp. 145-158.

Scheyvens, R., Griffin, A. L., Jocoy, C. L., Liu, Y. and Bradford, M. (2008) Experimenting with active learning in geography: dispelling the myths that perpetuate resistance, Journal of Geography in Higher Education, 32(1), pp. 51-69.

Scott, I., Fuller, I. and Gaskin, S. (2006) Life without fieldwork: some lecturer's perceptions of geography and environmental science fieldwork, Journal of Geography in Higher Education, 30(1), pp. 161-171.

Spronken-Smith, R., Bullard, J., Ray, W., Roberts, C. and Keiffer, A. (2008) Where might sand dunes be on Mars? Engaging students through inquiry-based learning in geography, Journal of Geography in Higher Education, 32(1), pp. 71-86.

Stanier, L. (1997) Peer assessment and group work as vehicles for student empowerment: a module evaluation, Journal of Geography in Higher Education, 21(1), pp. 95-98.

Thanasoulas, D. (2000) What is learner autonomy and how can it be fostered? The Internet TESL Journal, 6(11). Available at http://iteslj.org/Articles/Thanasoulas-Autonomy.html (accessed 14 October 2009).

Tinsley, H. M. (1996) Training undergraduates for self-directed field research projects in physical geography: problems and possible solutions, Journal of Geography in Higher Education, 20(1), pp. 55-64. 
Walkington, H. (2008) Quality enhancement of the student experience through undergraduate research opportunities - the impact of undergraduate research journals. Available at http://aces.shu.ac.uk/support/staff/HEA Harrogate/Helen Walkington.doc (accessed 27 November 2010).

Walkington, $H$. and Jenkins, A. (2008) Embedding undergraduate research publication in the student learning experience: ten suggested strategies, Brookes E-Journal of Learning and Teaching 2(3). Available at http://bej|t.brookes.ac.uk/article/embedding undergraduate research publication in the student learning experi/ (accessed 5 April 2010).

Zetter, R. (2002) Developing the link - enhancing the relationship between teaching and research in the built environment disciplines. Paper presented at the Housing Studies Association Autumn Conference 2002. Available at http://www.brookes.ac.uk/schools/planning/ltrc/documents/papers/HousingEducation2002. doc (accessed 27 November 2010). 


\section{Tables and Figures}

Section 1: Field observation and recording

- Unmodified field notes, explanations and interpretations*

- Field sketches and sketch maps*

- Correct site descriptions (e.g. grid reference, location, north point, general site description)

- Raw field data collected (e.g. stream conductivity, TDS and/or pH measurements, block fabric, ploughing boulder dimensions)*

- Other information collected in the field (e.g. tourism leaflets)

- Post-field course reflections on field observation and recording*

Section 2: Data presentation and analysis

- Examples of different approaches to presenting data (e.g. rose diagrams, scatterplots, histograms, tables of data, maps) ${ }^{\star}$

- Analyses of data (e.g. statistical tests)*

- Preliminary interpretations of data

- Post-field course reflections on data presentation and analysis*

Section 3: Integrating field and theoretical concepts

- Two page contribution to the Field Guide on an agreed topic*

- Evidence of generic post-fieldwork reading (e.g. reflective paper summaries or abstracts with annotations, an annotated bibliography)*

- Evidence of further reading about specific geomorphic features or processes

- A further reading list for specified features

${ }^{*}$ These are required elements

Table 1: Examples of evidence for the assignment 1 portfolio

\begin{tabular}{|l|l|}
\hline Quality of submitted work & $\begin{array}{l}\text { Authorship in Field } \\
\text { Guide }\end{array}$ \\
\hline $\begin{array}{l}\text { The student's submission can be included as it stands, } \\
\text { with only minor formatting and typographical corrections }\end{array}$ & $\begin{array}{l}\text { The student is sole } \\
\text { author }\end{array}$ \\
\hline $\begin{array}{l}\text { Minor intellectual intervention is required from the editor } \\
\text { (tutor) to correct errors, add omitted material or remove } \\
\text { superfluous material }\end{array}$ & $\begin{array}{l}\text { The tutor is second } \\
\text { author }\end{array}$ \\
\hline $\begin{array}{l}\text { Moderate to major intellectual intervention is required } \\
\text { from the editor (tutor) }\end{array}$ & The tutor is first author \\
\hline The material requires re-writing & The tutor is sole author \\
\hline
\end{tabular}

Table 2: 'Rules' for authorship in the Field Guide 


\begin{tabular}{|l|l|}
\hline Stage & Action \\
\hline 1 & Students submit a draft paper to the journal editor (the tutor). \\
\hline 2 & $\begin{array}{l}\text { Anonymised copies of draft papers are re-distributed among the cohort and each } \\
\text { student asked to provide peer review comments on the paper allocated to them. The } \\
\text { tutor, in the editor's role, also provides detailed feedback on each of the papers. }\end{array}$ \\
\hline 3 & $\begin{array}{l}\text { Marked-up manuscripts and peer-review comments are copied and returned to the } \\
\text { originating author. }\end{array}$ \\
\hline 4 & Final, corrected papers are submitted to the editor for 'publication'. \\
\hline
\end{tabular}

Table 3: Stages in the simulated peer-review process for assignment two

\section{For each class, all or most of the comments will apply.}

First class (70-100): High level of understanding of theoretical basis for research with considerable evidence of appropriate reading and synthesis of published work. Excellent research design and highly appropriate methodology. Excellent presentation of results and appropriate use of statistical or other quantitative and qualitative analytical methods. Well written, clear communication, well structured and coherent. Expression, style and grammar excellent. Clear evidence of intelligent interpretation and assimilation of reviewers comments. Demonstrates insight and perceptiveness with elements of innovation. A commendable degree of academic understanding and criticality. Excellent, outstanding, brilliant.

Upper second (60-69): Good understanding of theoretical basis for research with significant evidence of appropriate reading and synthesis of published work. Good research design and use of appropriate methodology. Good presentation of results and appropriate use of statistical or other quantitative and qualitative analytical methods, demonstrating an ability to criticize, evaluate and analyse data. Generally well written, well structured and coherent. Expression, style and grammar good. Evidence of good interpretation and assimilation of reviewers comments. Demonstrates a firm grasp of the majority of material. Commendable degree of academic understanding and criticality. Good or very good.

Lower second (50-59): Reasonable understanding of theoretical basis for research with some evidence of appropriate reading but limited or inappropriate. A rather descriptive approach to the review of published work. Competent research design and use of appropriate methodology. Presentation of results satisfactory with some attempt to make use of appropriate statistical or other quantitative and qualitative analytical methods.

Demonstrates some ability to criticize, evaluate and analyse data but arguments are sometimes weak or poorly developed. Moderately well written and structured with reasonable expression, style and grammar. Some evidence that an attempt has been made to incorporate the reviewers comments. Demonstrates some grasp of the material. Adequate degree of academic understanding and criticality but lacking originality. Adequate or competent.

Third class (40-49): Weak understanding of theoretical basis for research. Little evidence of wider reading or inappropriate. Major omissions and/or only partially relevant. A descriptive approach to the review of published work with little evidence of genuine understanding. Weak or flawed research design and inappropriate use of methodology. Presentation of results weak with little attempt to make use of statistical or other quantitative and qualitative analytical methods. Demonstrates little ability to criticize, evaluate or analyse data, with obscure or irrelevant arguments. Poor writing style and limited expression and grammar. Weak structure or incoherent in places. Little evidence that any attempt has been made to incorporate the reviewers comments. Demonstrates a weak grasp of the material. Weak degree of academic understanding but lacking criticality and originality. Weak or unbalanced.

Fail (0-39): Unsatisfactory evidence of understanding of theoretical basis for research. Little or no evidence of wider reading. Major omissions and errors. An entirely descriptive approach to the review of published work. Fundamentally flawed research design and inappropriate use of methodology. Poor presentation of results with little or no attempt to make use of statistical or other quantitative and qualitative analytical methods.

Demonstrates no critical ability and little ability to analyse and interpret the data meaningfully. Poor writing style and limited expression and grammar throughout. Generally poorly structured and/or incoherent. Little or no evidence that any attempt has been made to incorporate the reviewers comments. Demonstrates little grasp of the material. Unsatisfactory evidence of academic understanding, lacking criticality and originality. For marks above 30; generally unsatisfactory but perhaps with some redeeming features (eg some evidence of preparation, limited understanding, some reflective thought). Unsatisfactory 


\section{Overall student reflections on the module}

- Well they say you learn geography through the soles of your feet and I agree! I feel I have learned more in one week than the entirety of my first and second years.

- Nothing was given to us on a plate.... we were challenged to explain features and give our own interpretations. Initially this was daunting but ultimately pleasurable to do. Again, I actually surprised myself in being able to achieve this.

- I really liked the fact that because we were a small group the seminars were less formal.

- The freedom to include almost whatever was really good as it allowed flexibility on things we understood better, found more interesting etc. It was nice to do a reflective piece of work on our experience.

- The overall fieldtrip was fantastic! A really good, educational experience and I feel because I was out in the field looking at glaciers, striations, sandurs etc I know a lot more about them than if I was to just read a textbook.

- The field course was amazing. The things we saw and did in such a short space of time. It was exhausting but most certainly worth it.

- In general, a fantastic trip, learned a lot, made new friends and did not stop laughing!

\section{Student perceptions of academic and intellectual development}

- We were challenged.

- The peer assessment - it was very stimulating and useful.

- Assignments - they were interesting and enjoyable to complete.

- Conducting the project gave me a chance to conduct my own project from which I have learned a lot.

- The Field Guide and associated presentations - stimulated research before the trip.

- We learned new skills and developed existing ones.

- The assignments helped me to demonstrate my understanding of geomorphological processes.

- Seeing things that are not as understandable through a textbook.

Table 5: Selected student quotations from the module evaluation

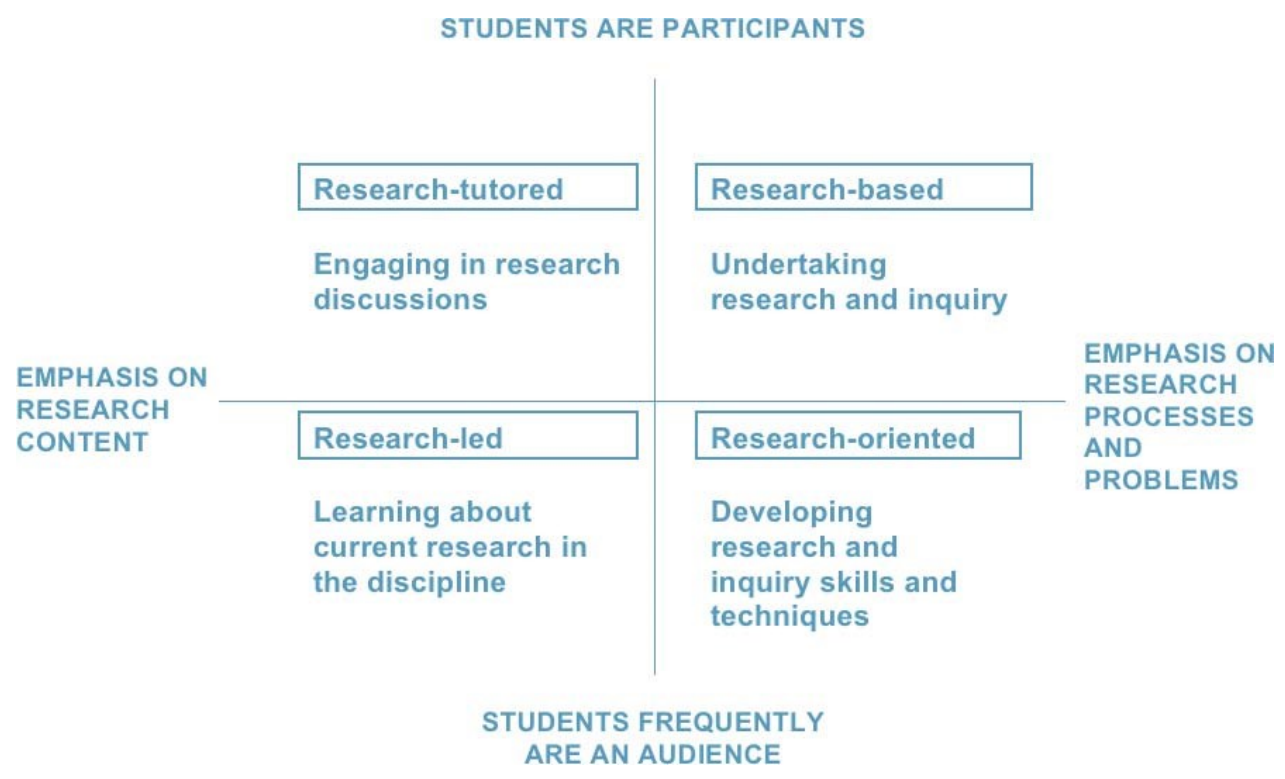

Figure 1: Curriculum design and the research-teaching nexus (re-drawn from Healey 2005b, modified from an original concept by Griffiths 2004). 


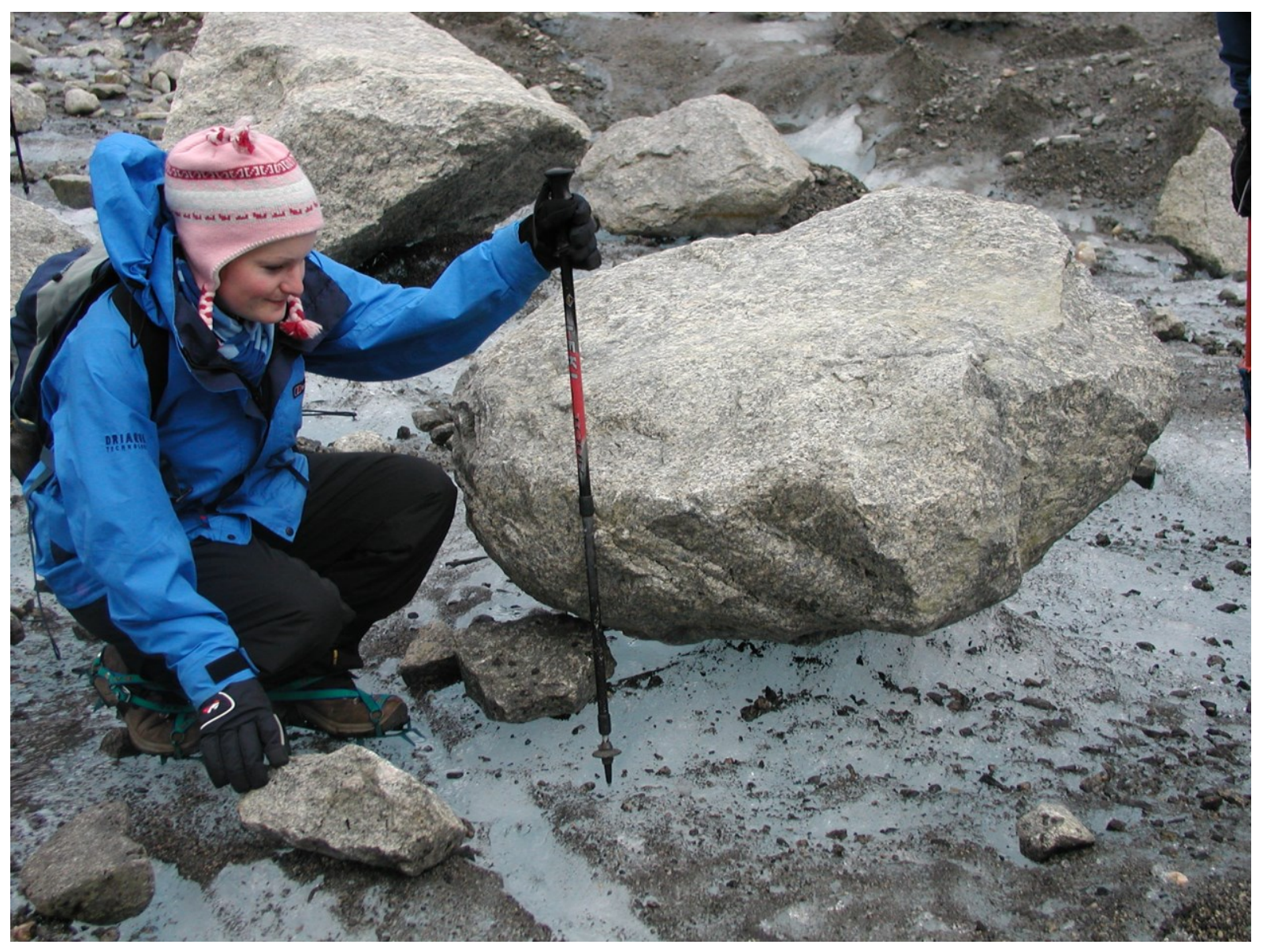

Figure 2: A student about to provide an informal presentation and explanation of a 'glacier table'. 


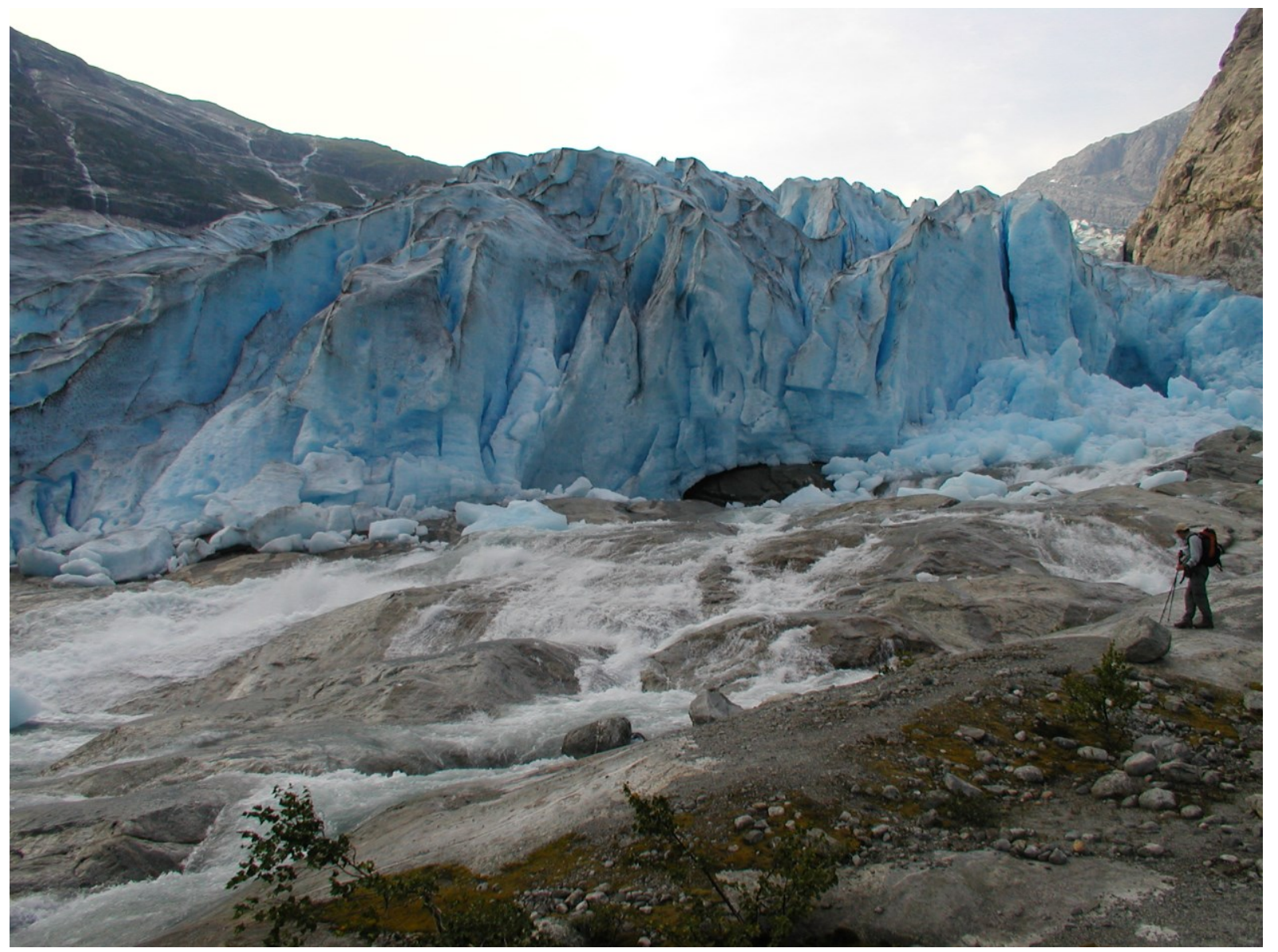

Figure 3: The immediate foreland of Nigardsbreen glacier (meaning 'new farm glacier'), Jostedals, Norway.

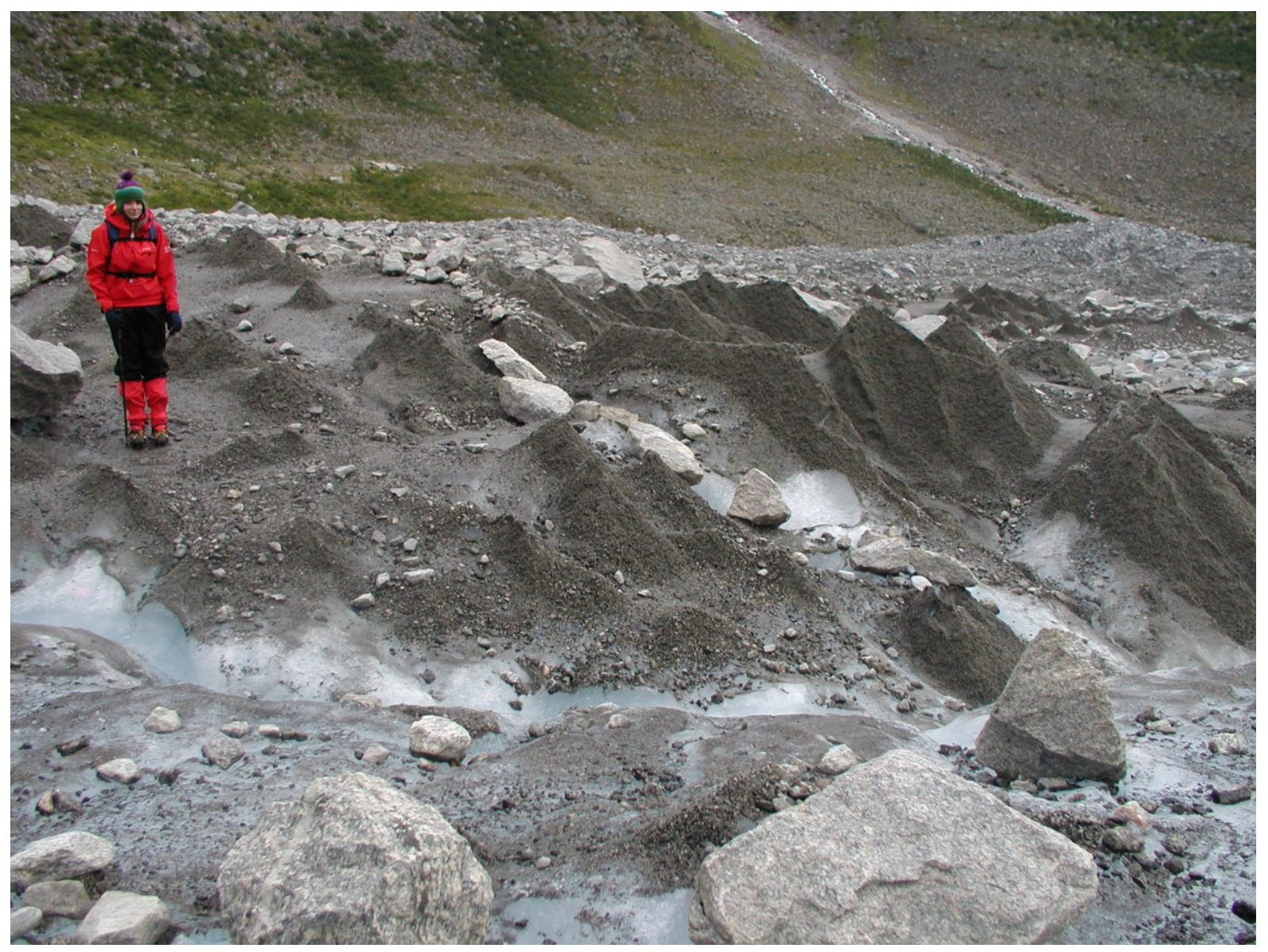


Figure 4: Taking the opportunity to observe unusual features and deepen academic understanding of process and material interactions.

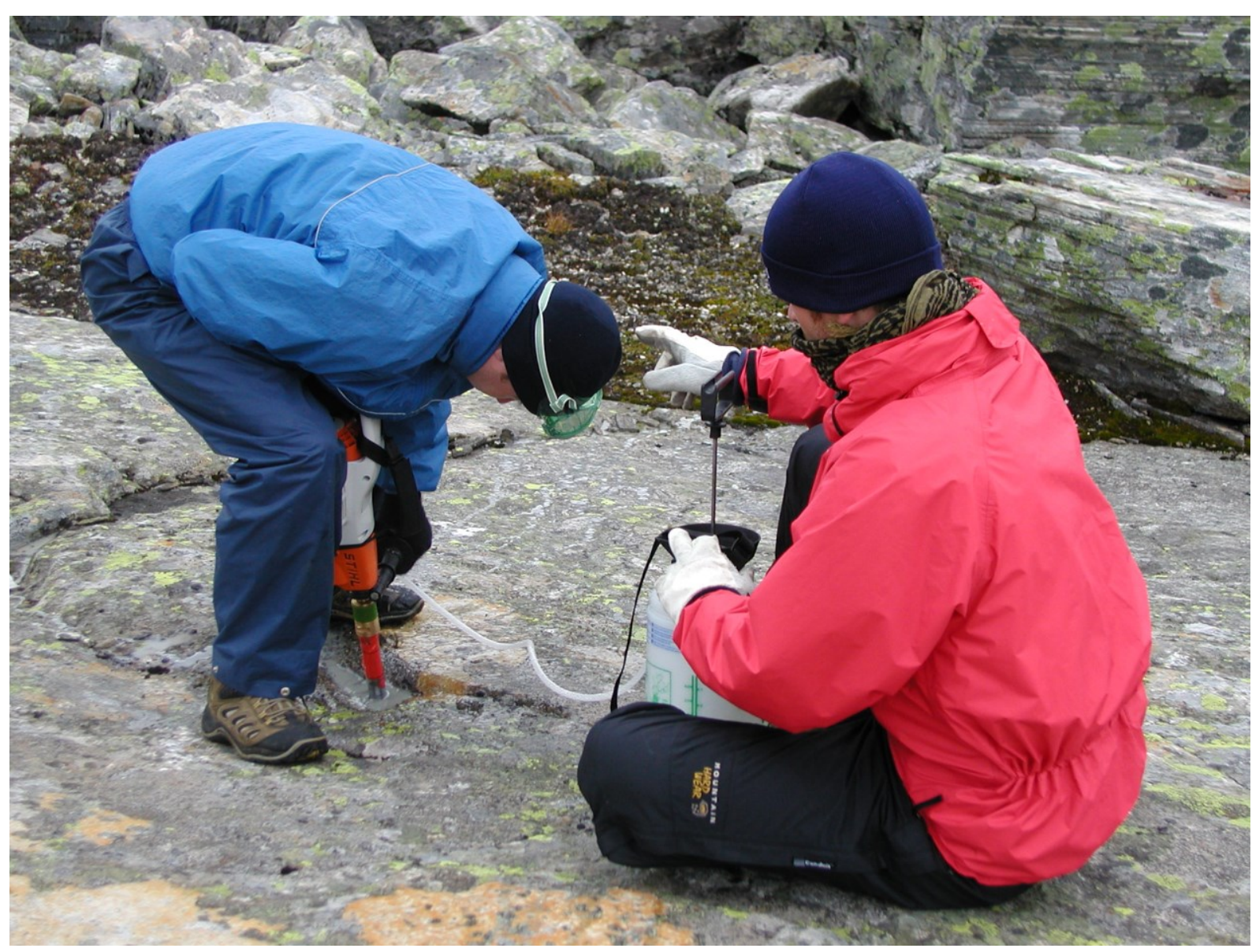

Figure 5: Close collaboration between students learning new, advanced field techniques and potentially transferable practical skills. 


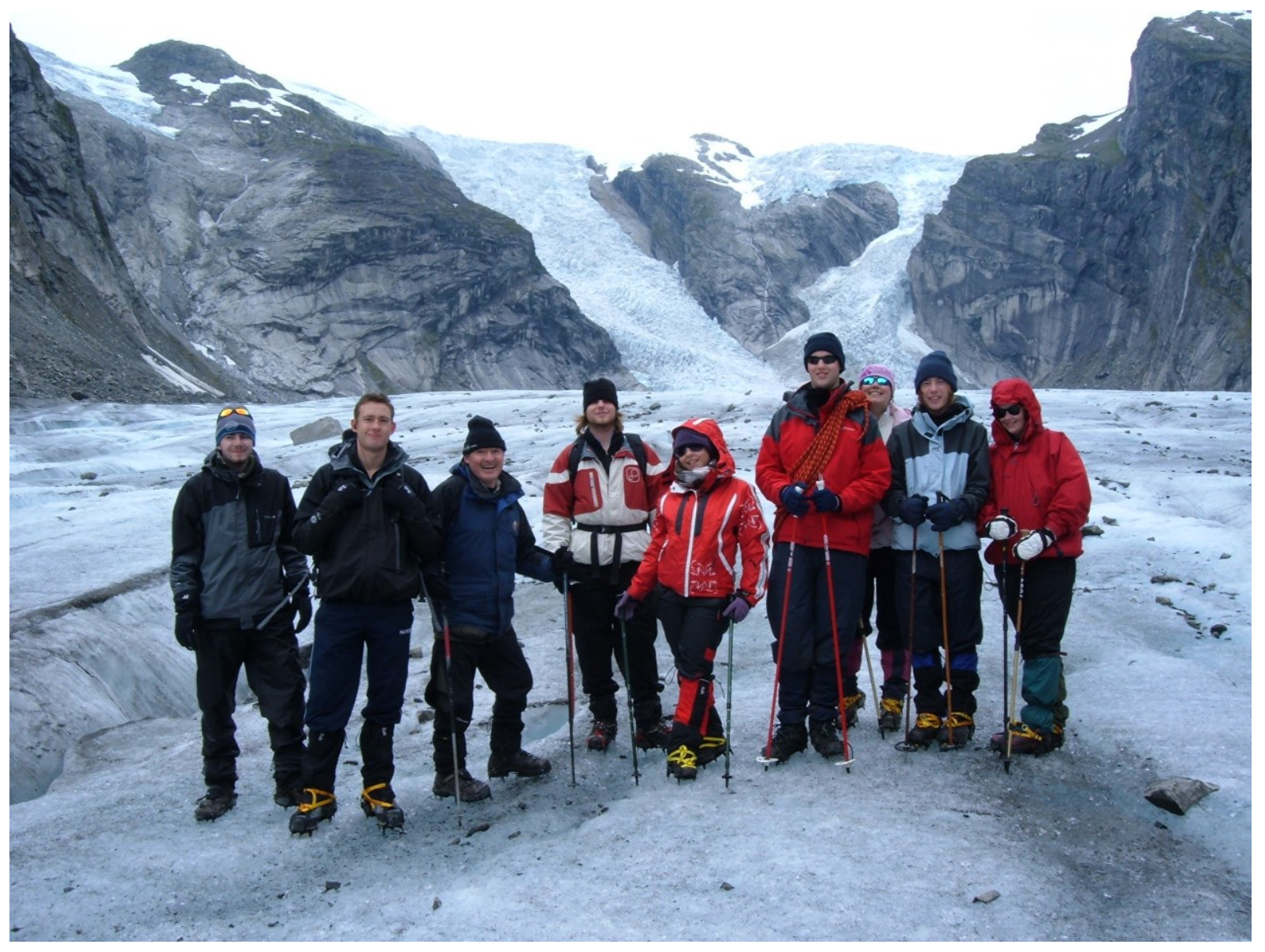

Figure 6: Enjoying a shared group moment in a spectacular landscape. 